\title{
Phytochemistry and Biology of Loranthus parasiticus Merr, a Commonly Used Herbal Medicine
}

\author{
Soheil Zorofchian Moghadamtousi, Muhamad Noor Alfarizal Kamarudin, \\ Chim Kei Chan, Bey Hing Goh and Habsah Abdul Kadir \\ Biomolecular Research Group, Biochemistry Program \\ Institute of Biological Sciences, Faculty of Science \\ University of Malaya, 50603 Kuala Lumpur, Malaysia
}

\begin{abstract}
Loranthus parasiticus Merr (L. parasiticus) is a member of Loranthaceae family and is an important medicinal plant with a long history of Chinese traditional use. L. parasiticus, also known as Sang Ji Sheng (in Chinese), benalu teh (in Malay) and basokisei (in Japanese), is a semiparasitic plant, which is mostly distributed in the southern and southwestern regions of China. This review aims to provide a comprehensive overview of the ethnomedicinal use, phytochemistry and pharmacological activity of L. parasiticus and to highlight the needs for further investigation and greater global development of the plant's medicinal properties. To date, pharmacological studies have demonstrated significant biological activities, which support the traditional use of the plant as a neuroprotective, tranquilizing, anticancer, immunomodulatory, antiviral, diuretic and hypotensive agent. In addition, studies have identified antioxidative, antimutagenic, antiviral, antihepatotoxic and antinephrotoxic activity. The key bioactive constituents in $L$. parasiticus include coriaria lactone comprised of sesquiterpene lactones: coriamyrtin, tutin, corianin, and coriatin. In addition, two proanthocyanidins, namely, AC trimer and (+)-catechin, have been recently discovered as novel to $L$. parasiticus. L. parasiticus usefulness as a medicinal plant with current widespread traditional use warrants further research, clinical trials and product development to fully exploit its medicinal value.
\end{abstract}

Keywords: Loranthus parasiticus; Scurrula parasitica; Loranthaceae; Mistletoe; Biological Activity; Coriaria Lactone; Review.

Correspondence to: Dr. Habsah Abdul Kadir, Biomolecular Research Group, Biochemistry Program, Institute of Biological Sciences, Faculty of Science, University of Malaya, Kuala Lumpur 50603, Malaysia. Tel: $(+60)$ 3-7967-4363, Fax: (+60) 3-7967-4178, E-mail: habsah@um.edu.my 


\section{Introduction}

Nutraceuticals, including an extensive range of categories such as functional foods, dietary supplements and herbal products, provide various medicinal or health benefits for the treatment and prevention of different ailments and diseases. The phytochemicals and active constituents in plants have been associated with numerous health promoting and disease controlling benefits (Karim and Azlan, 2012). Therefore, the need for enhancing our knowledge concerning these plants towards the development of new pharmaceutical products necessitates extensive investigation of the plants, their biological activities and their key bioactive phytochemicals. Additionally, the fact that detailed scientific scrutiny only covered a limited number of plant species highlighted an even greater need for these studies to be undertaken (Jothy et al., 2012). Plants with a long history of use in folk medicine were found to have a variety of phytochemicals and bioactivities for the potential treatment of different ailments and diseases (Duraipandiyan et al., 2006). One such plant with ethnomedicinal use that has been shown to have various biological activities is L. parasiticus. This review summarized the traditional use, phytochemistry, biological activities and possible mechanisms of $L$. parasiticus bioactivities.

\section{Botanical Description and Distribution}

L. parasiticus, known also as Cichlanthus scurrula (L.) Tiegh., Loranthus chinensis var. formosanus Lecomte, Scurrula parasitica L., Loranthus scurrula L. and Taxillus parasiticus (L.) S.T. Chiu, with a widespread distribution in the south and southwestern parts of China (Flora of China Editorial Committee, 2003; Wong et al., 2012a) is a member of the Loranthaceae family comprising 73 genera and 900 species, which generally consists of aerial hemiparasitic plants. Aerial parasites include plants commonly known as "mistletoes" that have arisen five times in separate lineages within the order (Vidal-Russell and Nickrent, 2008). Mistletoes are hemiparasitic shrubs that attach to the host stems in order to absorb mineral nutrients and water, although they provide their own carbohydrates through photosynthesis (Griggs, 1991). Because of this metabolic attachment to the host trees, their

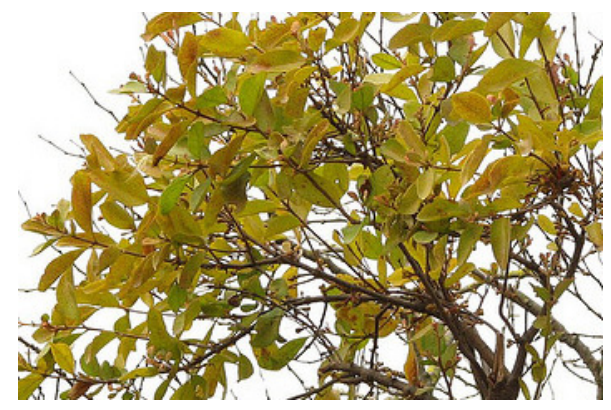

(A)

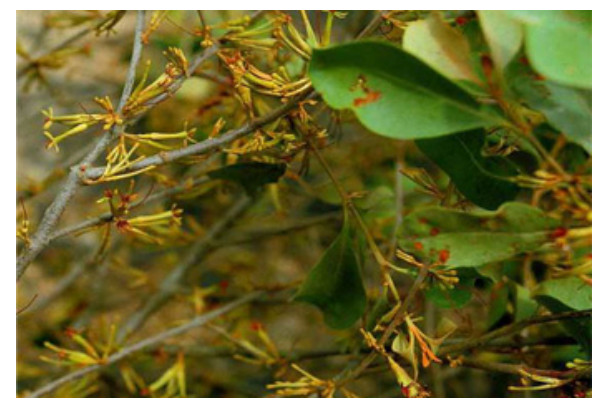

(B)

Figure 1. The Loranthus parasiticus Merr (A), the appearance of the flowers and leaves (B). 
phytoconstituents and hence biological activities are strongly dependent on their respective hosts (Fukunaga et al., 1989; Osadebe et al., 2004). Additionally, recent studies revealed that the parasitic life of $L$. parasiticus (Fig. 1) may in turn affect the metabolism of the host tree. For example, an investigation of the phytoconstituents of Osmanthus fragrans and Cinnamomum burmannii injured by L.parasiticus revealed a notable decrease in the level of chlorophyll and total soluble sugar in the leaves, albeit the proline content of the leaves was elevated (Qin et al., 2010).

\section{Ethnopharmacology}

L. parasiticus is traditionally believed to have diuretic, tranquilizing and hypotensive properties via an arterial vasodilation effect and inhibition of polio viruses (Wong et al., 2012b). The diuretic effect of $L$. parasiticus according to folk medicine was substantiated by the in vivo study of flavonearabinoside isolated from L. parasiticus on anesthetized dogs and unanesthetized rats. The study revealed a notable increase in the urine volume of tested animals (Shao-Xyan et al., 1959). In southwestern China, L. parasiticus has been used in ethnomedicine as a shock therapy for the treatment of schizophrenia (Okuda et al., 1987). In addition, L. parasiticus was suggested to have a variety of uses for the liver, brain, kidney, and bone, and prevents miscarriage and expels wind-damp (Okuda et al., 1987), although no scientific report has corroborated these medicinal properties. It is also believed, in traditional Chinese medicine, that branches of $L$. parasiticus have cytotoxic activity against cancer in humans. It is also believed that they can improve the immune system and aid in cancer control.

\section{Phytochemistry}

It has been demonstrated that Loranthus species are generally a rich source of various bioactive compounds (Wong et al., 2012b). Investigation of the general composition of L. parasiticus revealed that it contains pronounced levels of crude fiber amounting to $82.28 \%$. It also contains $9.21 \%$ of moisture, $2.44 \%$ of ash, $2.70 \%$ of crude protein, $0.77 \%$ of crude fat and $2.60 \%$ of other components (Chen et al., 2003). Coriaria lactone is a mixture of compounds isolated from L. parasiticus parasitic on Coriaria sinica (C. sinica). Coriaria lactone is the most important group of compounds isolated from L. parasiticus and includes sesquiterpene lactones such as coriamyrtin, tutin, corianin and coriatin (Okuda and Yoshida, 1967a,b; Wu and Zhang, 1984). These sesquiterpenes were isolated from the ethanol extract of $L$. parasiticus leaves parasitic on the twigs of $C$. sinica. The isolation of these sesquiterpenoids from $C$. sinica also suggested that they have been transported from the host tree and accumulated in L. parasiticus without being metabolized. Additionally, this also demonstrated the strong host dependency for phytoconstituents by L. parasiticus and hence, for biological activity (Okuda et al., 1987). Two known proanthocyanidins of $\mathrm{AC}$ trimer and (+)-catechin were identified from the aqueous fraction of $L$. parasiticus leaves by comparing ${ }^{1} \mathrm{H} \mathrm{NMR}$ and ${ }^{13} \mathrm{C}$ NMR spectra with literature values (Wong et al., 2012b). Figure 2 and Table 1 show the chemical structures of compounds isolated from L. parasiticus and their bioactivities. 


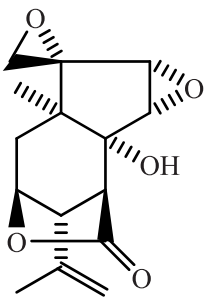

coriamyrtin

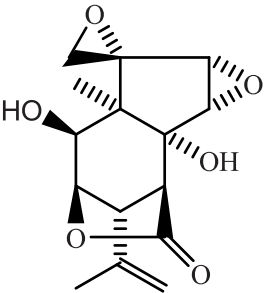

tutin

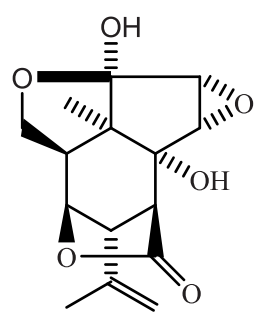

corianin

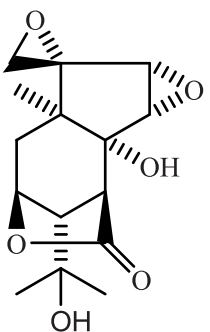

coriatin<smiles>Oc1cc(O)c2c(c1)OC(c1ccc(O)c(O)c1)C(O)C2</smiles>

$(+)$ - catechin<smiles>Oc1cc(O)c2c(c1)O[C@H](c1ccc(O)c(O)c1)[C@H](O)[C@H]2c1c(O)cc(O)c2c1O[C@H](c1ccc(O)c(O)c1)[C@H](O)[C@H]2c1c(O)cc(O)c2c1O[C@H](c1ccc(O)c(O)c1)[C@H](O)C2</smiles>

AC trimer

Figure 2. Chemical structures of compounds isolated from L. parasiticus harvested from the twigs of C. sinica.

Table 1. Biological Activity of Compounds Isolated From Loranthus parasiticus

\begin{tabular}{lccc}
\hline Part of Plant Used & Compound & Biological Activity & Reference \\
\hline Leaves & AC Trimer & Neuroprotection & (Wong et al., 2012) \\
& $(+)$-Catechin & Neuroprotection & (Wong et al., 2012) \\
& Coriamyrtin & Anti-schizophrenia Activity & (Okuda et al., 1987) \\
& Tutin & Anti-schizophrenia Activity & (Okuda et al., 1987) \\
& Corianin & Anti-schizophrenia Activity & (Okuda et al., 1987) \\
& Coriatin & Anti-schizophrenia Activity & (Okuda et al., 1987) \\
\hline
\end{tabular}

\section{Bioactivity}

Herbal products have constituted the basis of ethnomedicines for centuries and represent valuable materials in medicine (Xutian et al., 2009; Zhao et al., 2009; Wang et al., 2011). As a result of biodiversity leading to many different phytoconstituents in plant species, a wide variety of pharmacological activities have been the basis for herbal medicines. This includes plant-derived drugs for the treatment of different ailments and 
diseases as a significant portion of modern medicine (Wang et al., 2012). L. parasiticus, as a traditional herb of China, Japan, Indonesia, Malaysia and Taiwan, has been tested and shown to exhibit a range of biological activities including antioxidant, neuroprotective, antinephrotoxic, antiviral and antihepatotoxic activities. Moreover, L. parasiticus is one of the few Chinese medicinal herbs formulated into healthy herbal drinks in food processing pilot plant that did not reveal any mutagenicity effect against Salmonella typhimurium tester strains TA100 and TA98 when assessed by the Ames mutagenic test. In addition, the water extract of the L. parasiticus branch and leaf demonstrated $81.1 \%$ and $13.9 \%$ inhibition against the mutagenic action of 4-nitroquinoline N-oxide (NQNO) on S. typhimurium TA98 and TA100, respectively. Based on these results and the antimutagenic effect of $L$. parasiticus, it is suggested that it can be considered a safe herbal drink with health-promoting benefits for the public (Chen et al., 2003). Nevertheless, a single chain cytotoxic protein with a molecular weight of approximately $43 \mathrm{KD}$ was also isolated from $L$. parasiticus. This protein was found to be toxic against myeloma cells with $50 \%$ inhibitory dose $\left(\mathrm{ID}_{50}\right)$ of $1.0 \times 10^{-7} \mathrm{~mol} / \mathrm{L}$, and it also showed an inhibitory effect against protein synthesis in a lysate of rabbit reticulocytes with an $\mathrm{ID}_{50}$ value of $7.0 \times 10^{-6} \mathrm{~mol} / \mathrm{L}$ (Zhou et al., 1993). The methanol extract also exhibited strong antinociceptive potential which is attributed to the metabolite from the host tree (Mahajan et al., 2013).

\section{Antioxidative Activity}

Reactive oxygen species (ROS), which are chemical species of molecules or atoms with unpaired electrons on their outermost orbit, are produced during normal metabolism when oxygen is reduced to water (Desai et al., 2008). Elevation of the intracellular ROS level causes oxidative stress, which results in metabolic impairments and cell death due to a variety of physiological and biochemical lesions (Chance et al., 1979). The isolation of antioxidants from various plants creates an upsurge of interest in recent studies for their major role in exerting antioxidative health promoting activity by counteracting the effects of ROS (Gan et al., 2010; Liao et al., 2012; Zhang et al., 2012). The methanol extracts from 50 medicinal plants used for the treatment of rheumatic diseases were screened for antioxidant activity by Trolox equivalent antioxidant capacity (TEAC) and ferric-reducing antioxidant power (FRAP) tests. According to the study, L. parasiticus, with the highest total phenolic contents (by Folin-Ciocalteu method), was found to possess the strongest antioxidant activity. The results exhibited the values of $580.02 \mu \mathrm{mol} \mathrm{Fe}(\mathrm{II}) / \mathrm{g}$ and $457.00 \mu \mathrm{mol}$ Trolox/g of dry weight of plant material for the FRAP and TEAC assays, respectively (Gan et al., 2010). In addition, several studies suggested a close correlation between the antioxidant activities of medicinal plants and the concentration of their phenolic compounds (Djeridane et al., 2006). The various extracts obtained from the leaves and branches of $L$. parasiticus, when evaluated for their antioxidant activity by means of 2,2-diphenyl-1-picrylhydrazyl (DPPH) free radical scavenging activity and reducing power, showed that the water extract exhibited the highest value of antioxidant activity of $73.48 \%$ (Chen et al., 2003). The methanol extract, ethyl acetate and aqueous 
fractions of $L$. parasiticus leaves revealed a dose-dependent antioxidant activity. The aqueous fraction indicated the strongest reducing power activity yielding the lowest $\mathrm{IC}_{50}$ values of $1.05 \mathrm{mg} / \mathrm{mL}$ and $16.82 \mu \mathrm{g} / \mathrm{mL}$ for lipid peroxidation and DPPH radical scavenging activities, respectively. The aqueous fraction also produced the highest total phenolic content comprising phenolic acids, flavonoids, anthocyanins and tannins with 56.51 GAE (gallic acid equivalents)/g $\mathrm{g}_{\mathrm{DW}}$ (Wong and Kadir, 2011), thus suggesting the potential use of L. parasiticus plant extracts as a natural source of antioxidant.

\section{Neuroprotective Activity}

Apoptosis is a selective, genetically regulated pathway for cell deletion (Elmore, 2007). In the early 1990s, it was proven that hydrogen peroxide $\left(\mathrm{H}_{2} \mathrm{O}_{2}\right)$-induced ROS generation could be a possible pathway leading to apoptosis (Pierce et al., 1991). ROS was found to play a critical role in neurodegeneration induced by different pathological disorders such as ischemia, excitotoxicity and oxidative stress. Neuronal death due to ROS-induced oxidative injury is an important factor involved in various chronic and acute neurodegenerative diseases. In addition, there is also accumulating evidence indicating the involvement of ROS in neurodegenerative diseases, including hemorrhagic and ischemic stroke, Parkinson's and Alzheimer's diseases (Lipton, 1999; Eckert et al., 2003; Jenner, 2003; Klein and Ackerman, 2003). Hence, the management of either chronic or acute neurodegenerative diseases necessitates a search for alternative treatments isolated from natural sources. The neuroprotective activity of the ethanol extract, ethyl acetate and aqueous fractions from $L$. parasiticus leaves when evaluated against $\mathrm{H}_{2} \mathrm{O}_{2}$-damaged NG108-15 hybridoma cells using the MTT cell viability assay, has shown that the aqueous fraction exhibited the strongest neuroprotective activity yielding $78.00 \%$ cell viability in a dose-dependent manner. The aqueous fraction also possessed the highest total phenolic content (Wong et al., 2011). Pretreatment with the aqueous fraction restored reduced intracellular glutathione (GSH), a major endogenous antioxidant and it also reduced the production of ROS induced by $\mathrm{H}_{2} \mathrm{O}_{2}$. Significantly attenuated apoptotic properties, including the disruption of mitochondrial membrane potential, externalization of phosphatidylserine and reduction of $\mathrm{H}_{2} \mathrm{O}_{2}$-induced sub- $\mathrm{G}_{1}$ population, confirmed the neuroprotective effect of the L. parasiticus aqueous fraction (Wong et al., 2012a). The isolated compounds, AC trimer and (+)-catechin, from the aqueous fraction of L. parasiticus leaves showed a potent neuroprotective activity assessed by the MTT assay in NG108-15 hybridoma cells with $93.38 \%$ and $102.41 \%$ cell viability at $1 \mathrm{mM}$, respectively, compared to $78.49 \%$ cell viability for resveratrol as a standard positive control. The compound (+)-catechin exerted the strongest neuroprotective activity through the reversal of the effects on intracellular ROS generation, externalization of phosphatidylserine, mitochondrial membrane potential dissipation and sub- $\mathrm{G}_{1}$ apoptotic fraction on NG10815 cells (Wong et al., 2012b). These results, for both crude extracts and isolated phytochemicals, lend strong support to the traditional use of the plant as a neuroprotective agent in ethnomedicine. 


\section{Anti-schizophrenia Activity}

Schizophrenia is a severe mental disorder characterized by delusions, hallucinations and cognitive deficits and has a roughly $1 \%$ risk in a lifetime with heritability estimated at up to 80\% (Cardno and Gottesman, 2000; Sullivan et al., 2003). World Health Organization (WHO) reported 24 million suffering from schizophrenia worldwide (WHO, 2013) with the peak ages of onset at 20-28 years and 26-32 years in males and females, respectively (Castle et al., 1991). Several studies have shown the correlation of nutritional factors and diet with the outcome and severity of schizophrenia (McCreadie, 2003; Peet, 2004). L. parasiticus is used in ethnomedicine as a shock therapy for schizophrenia in the southwestern part of China. A mixture of coriaria lactones from L.parasiticus was used for the treatment of schizophrenia. Either the aqueous extract of L. parasiticus or a mixture of crystalline sesquiterpenes comprising nontoxic coriatin and corianin with comparable activity to electric shock or insulin has been used for the catatonia treatment by muscle injection in hospitals of various areas of China. Catatonia, which is associated with the psychiatric condition of schizophrenia, is a condition of neurogenic motor immobility with behavioral abnormality demonstrated by stupor (Deuschle and Lederbogen, 2001). The results demonstrated that tutin and coriamyrtin with strong catatonic action in mice were effective components of L. parasiticus for the shock therapy (Okuda et al., 1987).

\section{Antinephrotoxic Activity}

Drug development process for selecting new drug candidates concerns a crucial stage of nephrotoxicity analysis (Uehara et al., 2007). The kidney is an essential target for the toxic activity of drugs, xenobiotics, and oxidative stress due to its individual metabolism (Sohn et al., 2007; Wu et al., 2007). Attempting to identify the protective molecules that can protect the kidney with the least adverse side effects necessitates widespread research worldwide. A variety of plants have been used in ethnomedicine for the treatment of drugor toxin-induced renal diseases. The protective activity of 239 herbal medicines, when evaluated against cisplatin-induced nephrotoxicity, in HEK 293 cells using the MTS assay, revealed that $L$. parasiticus water extract displayed the third strongest recovery activity in a dose-dependent manner with $43.6 \%$ maximal recovery of cell viability and an $\mathrm{EC}_{50}$ (effective concentration of half-maximum response) value of $3.810 \times 10^{-10} \mathrm{mg} / \mathrm{mL}$. The cytotoxic and genotoxic activities of L. parasiticus water extract on damaged HEK 293 cells were also assessed by lactate dehydrogenase and comet tests. At 48 hours, the cytotoxic and genotoxic activity of the extract in treated cells was lower than that of the non-treated cells (cisplatin- treated HEK 293 cells) and it also exhibited a marked decrease in cytotoxicity (Sohn et al., 2009).

\section{Antiviral Activity}

Despite all the research and progress, human immunodeficiency virus (HIV) and its acquired immunodeficiency syndrome (AIDS) are still the obtrusive problem of the 
medical world due to the widespread and uncontrollable pandemic of AIDS and its casualty. Aspartyl protease of HIV has a critical role for appropriate virion assembly and maturation. Thus, finding new compounds that can inhibit HIV protease is a promising way for the production of immature and non-infectious viral particles and hence, for rational drug design against AIDS (Seelmeier et al., 1988; McQuade et al., 1990). Some studies showed the inhibitory effect against HIV-1 protease by some natural compounds (Brinkworth et al., 1992; Xu et al., 1996). Thus, folkloric medicines of natural products are a possible source for the discovery of new anti-AIDS agents. A study of the aqueous extract isolated from 75 various traditional medicines used as ethnomedicine in China, Indonesia and Japan investigated the possible inhibitory activity against HIV-1 protease assessed by fluorogenic assay. The aerial part of L. parasiticus at doses of $250 \mu \mathrm{g} / \mathrm{mL}$ and $25 \mu \mathrm{g} / \mathrm{mL}$ elicited $59.8 \%$ and $27.8 \%$ inhibition, respectively (Xu et al., 1996). In addition, an in vitro study of the water extract of $L$. parasiticus stems and branches exhibited inhibitory activity against HIV-1 induced cytopathogenicity in MT-4 cells with an $\mathrm{ED}_{50}$ (median effective dose) value of $27 \mu \mathrm{g} / \mathrm{mL}$, which is significantly lower than its $50 \%$ curative dose $\left(\mathrm{CD}_{50}=100 \mu \mathrm{g} / \mathrm{mL}\right)$. It also revealed suppressive activity on the formation of giant cells in cocultures of HIV-1-uninfected and -infected MOLT-4 cells with an effective dose and cytotoxic dose of $\geq 60 \mu \mathrm{g} / \mathrm{mL}$ and $\geq 3000 \mu \mathrm{g} / \mathrm{mL}$, respectively. The water extract also showed inhibitory effects on reverse transcriptase and protease of HIV-1 with $\mathrm{IC}_{50}$ values of $5 \mu \mathrm{g} / \mathrm{mL}$ and $260 \mu \mathrm{g} / \mathrm{mL}$, respectively (Otake et al., 1995). The methanol and water extracts of $L$. parasiticus whole plant exhibited an inhibitory effect on reverse transcriptase of avian myeloblastosis virus (AMV) using $(\mathrm{rA})_{n}-(\mathrm{dT})_{12-18}$ and $(\mathrm{rC})_{n}-(\mathrm{dG})_{12-18}$ as two kinds of template primers. The methanol and water extracts of L. parasiticus in the $(\mathrm{rA})_{n^{-}}$ $(\mathrm{dT})_{12-18}$ directed reaction revealed $\mathrm{IC}_{50}$ values of $50 \mu \mathrm{g} / \mathrm{mL}$ and $100 \mu \mathrm{g} / \mathrm{mL}$, respectively. However the results for the $(\mathrm{rC})_{n}-(\mathrm{dG})_{12-18}$ primer revealed $\mathrm{IC}_{50}$ values of $80 \mu \mathrm{g} / \mathrm{mL}$ and $8 \mu \mathrm{g} / \mathrm{mL}$ for the methanol and water extract, respectively (Kusumoto et al., 1992). L. parasiticus extract did not demonstrate appreciable cytotoxicity at the concentration where over $90 \%$ of reverse transcriptase was suppressed. In addition, a mixture of water extract of $L$. parasiticus with bovine serum albumin showed a significant reduction in the inhibition of reverse transcriptase from $94.5 \%$ to $12.7 \%$, suggesting that the extract may include compounds with high binding affinity for protein molecules, which can possibly interfere with reverse transcriptase activity. The results also revealed the presence of $5.8 \%$ tannin content in the water extract of L. parasiticus whole plant. A quantitative determination of the inhibitory plant extracts containing tannins suggested that samples with more than $5 \%$ of tannin can have a potent suppressive effect on reverse transcriptase (Kusumoto et al., 1992).

\section{Antihepatotoxic Activity}

Lack of effective treatment in modern medicine associated with poor positive influence of synthetic drugs on liver damage has urged searching for new herbal medicine with more effective hepatoprotective activity. A variety of ethnomedicinal plants and their formulations are being used for liver disorders so far (Ahmad and Tabassum, 2013; Pallab et al., 
2012). The study of 129 Formosan plants investigated the antihepatotoxic effect in primary cultured hepatocytes damaged by D-galactosamine and carbon tetrachloride. The ethanol extract of L. parasiticus stem was among the eight species having a marked inhibitory effect in both assay methods. It caused 50\% inhibition on glutamic-pyruvic transaminase (GPT) in both D-galactosamine and carbon tetrachloride damage in rat liver cells (Yang et al., 1987).

\section{Anticancer Activity}

An in vitro study on the aqueous extract isolated from $L$. parasiticus branches against three ovarian cancer cell lines, namely SKOV3, CAOV3 and OVCAR-3, when assessed by 3(4,5-dimethylthiazol-2-yl)-2,5-diphenyltetrazolium bromide (MTT) cell viability assay revealed cytotoxicity against the tested cell lines (Powell et al., 2003). An investigation on the anticancer effects of the flavonoid extracts of $L$. parasiticus harvested from different host trees suggested strong host-dependency on the anti-cancer potential. The flavonoid extract of $L$. parasiticus parasitizing on the Nernium indicum showed the lowest $\mathrm{IC}_{50}$ value of $0.60 \mathrm{mg} / \mathrm{L}$ on the human leukemia cell line HL-60. The flavonoid extract also induced apoptosis characterized by $\mathrm{AO} / \mathrm{EB}$ fluorescence staining, DNA fragmentation and cell cycle arrest at $\mathrm{G}_{0}-\mathrm{G}_{1}$ (Xiao et al., 2008). The antitumor investigation on the polysaccharides isolated from $L$. parasiticus leaves by water extraction and ethanol precipitation revealed a tumor inhibition rate of $54 \%$ on the sarcoma S180 growth in mice through Bax up-regulation and the down-regulation of Bcl-2, CyclinD1 and Ki-67 protein (Xiao et al., 2010). These results indicated that the in vivo and in vitro inhibition on the cancer cell proliferation and induction of apoptosis are possible anti-cancer mechanisms of L. parasiticus.

\section{Application in Epilepsy Investigations}

Epilepsy, characterized by hypersynchronization and hyperexcitability, is a group of heterogeneous brain disorders. Animal models of epilepsy, due to similar basic features, can provide useful information on the various syndromes and complex etiologies found in humans. Coriaria lactone isolated from L. parasiticus was shown to possess significant potential for the activation of the nervous system and induction of seizures and has been used to establish animal models of epilepsy (Tang et al., 1990; Guo et al., 1992) Various studies used these models for the investigation of epileptogenic mechanisms and the analysis of anti-epileptic drugs (Chai et al., 1989). Tutin, one of the major ingredients of coriaria lactone, was used in an in vitro study to investigate the epileptogenic effect and mechanism underlying the process in CA1 pyramidal cells of rat hippocampal slices. The results demonstrated that tutin may be an effective epileptogenic agent by inducing typical multiple epileptiform discharges in CA1 pyramidal cells of rat hippocampal slices. In addition, there is a possibility for the participation of the receptors of excitatory glutamate in especially the non-NMDA receptors in the genesis of tutininduced epileptiform discharges (Zhou et al., 2004). These results showed the potential 
of this compound towards the development of a new animal model of acute seizures induced by tutin (Zhou et al., 2006).

\section{Conclusion}

L. parasiticus plant, its extracts and isolated active principles, are proven to possess significant biological activities. The neuroprotective activity of $L$. parasiticus can contribute to the prevention and the reduction of the complications of neurodegenerative diseases and mental disorders. Catechin and AC Trimer have recently been identified as neuroprotective compounds from the aqueous extract of $L$. parasiticus. Coriaria lactone compound mixture isolated from $L$. parasiticus proved to have potential in developing animal models for epilepsy. Throughout our literature search it was observed that despite many studies that validated the ethnopharmacological uses of $L$. parasiticus, few areas that may limit the medicinal use of this plant have not been fully addressed to date. Many of the reported pharmacological studies used plant materials that are not well characterized and this leads to difficulty in reproducing the reported results. Further research will need to characterize and determine the effect of potentially neuro-protective compounds in extracts of the whole plant, which can lead to the discovery of new bioactive principles. Investigation on the biochemical and physiological functions of the isolated bioactive compounds and mechanisms underlying their action is considered vital for further development of the medicinal uses of L. parasiticus. Further investigation including clinical trials to exploit the plant's novel phytochemicals as potentially new pharmaceutical drugs is another area for further research. In addition, the toxicity test found in the literature is in reference to the methanol extract, thus further toxicity tests of the different extracts from all parts of the plant would provide important information on the safety or toxicity of potentially new preparations, which may provide wider clinical applications. It is hoped that this review would be a source of guidance and encouragement for the interested researchers to perform further in vitro, in vivo and clinical investigations on the activity of $L$. parasiticus and its constituents against different ailments and diseases.

\section{Acknowledgments}

The authors would like to thank the University of Malaya for providing the research grant (RP001-2012C) and High Impact Research (J-21010-73848).

\section{References}

Ahmad, F. and N. Tabassum. Preliminary phytochemical, acute oral toxicity and antihepatotoxic study of roots of Paeonia officinalis Linn. Asian Pac. J. Trop. Biomed. 3: 64-68, 2013.

Brinkworth, R.I., M.J. Stoermer and D.P. Fairlie. Flavones are inhibitors of HIV-1 proteinase. Biochem. Biophys. Res. Commun. 188: 631-637, 1992.

Cardno, A.G. and I.I. Gottesman. Twin studies of schizophrenia: from bow-and-arrow concordances to Star Wars Mx and functional genomics. Am. J. Med. Genet. 97: 12-17, 2000. 
Castle, D., S. Wessely, G. Der and R.M. Murray. The incidence of operationally defined schizophrenia in Camberwell, 1965-1984. Br. J. Psychiatry 159: 790-794, 1991.

Chai, H., Y. Xie, Q. Chen and Y. Huang. An experimental observation on the calmative and antiepileptic effects of a new synthetic drug SC1001-aminum intupaias. J. West China Univ. Med. Sci. 20: 21, 1989.

Chance, B., H. Sies and A. Boveris. Hydroperoxide metabolism in mammalian organs. Physiol. Rev. 59: 527-605, 1979.

Chen, W., Y.M. Weng and C.Y. Tseng. Antioxidative and antimutagenic activities of healthy herbal drinks from Chinese medicinal herbs. Am. J. Chin. Med. 31: 523-532, 2003.

Desai, P., R. Wadekar, G. Kedar and K. Patil. Free radical scavenging activity of aqueous extract of roots of Baliospermum montanum Muell-Arg. I. J. Green Pharm. 2: 31, 2008.

Deuschle, M. and F. Lederbogen. Benzodiazepine withdrawal-induced catatonia. Pharmacopsychiatry 34: 41-42, 2001.

Djeridane, A., M. Yousfi, B. Nadjemi, D. Boutassouna, P. Stocker and N. Vidal. Antioxidant activity of some Algerian medicinal plants extracts containing phenolic compounds. Food Chem. 97: 654-660, 2006.

Duraipandiyan, V., M. Ayyanar and S. Ignacimuthu. Antimicrobial activity of some ethnomedicinal plants used by Paliyar tribe from Tamil Nadu, India. BMC Complement. Altern. Med. 6: 35, 2006.

Eckert, A., U. Keil, C.A. Marques, A. Bonert, C. Frey, K. Schüssel and W.E. Müller. Mitochondrial dysfunction, apoptotic cell death, and Alzheimer's disease. Biochem. Pharmacol. 66: 1627-1634, 2003.

Elmore, S. Apoptosis: a review of programmed cell death. Toxicol. Pathol. 35: 495-516, 2007.

Flora of China Editorial Committee. Flora of China (Ulmaceae through Basellaceae). In: C.Y. Wu, P.H. Raven and D.Y. Hong (eds.) Fl. China. Science Press and Missouri Botanical Garden Press, Beijing and St. Louis, 2003, pp. 1-506.

Fukunaga, T., I. Kajikawa, K. Nishiya, K. Takeya and H. Itokawa. Studies on the constituents of the Japanese mistletoe, Viscum album L. var. coloratum OHWI grown on different host trees. Chem. Pharm. Bull. 37: 1300-1303, 1989.

Gan, R.Y., L. Kuang, X.R. Xu, Y. Zhang, E.Q. Xia, F.L. Song and H.B. Li. Screening of natural antioxidants from traditional Chinese medicinal plants associated with treatment of rheumatic disease. Molecules 15: 5988-5997, 2010.

Griggs, P. Mistletoe, myth, magic and medicine. The Biochemist 13: 3-4, 1991.

Guo, L., H. Chai, X. Liu and Y. Xie. Observations of synaptic efficacy and paired-pulse facilitation in area CA1 of hippocampal slices from Coriaria Lactone-kindled rats. Brain Res. 572: 269-272, 1992.

Jenner, P. Oxidative stress in Parkinson's disease. Ann. Neurol. 53: S26-S38, 2003.

Jothy, S.L., A. Torey, I. Darah, Y.S. Choong, D. Saravanan, Y. Chen, L.Y. Latha, S. Deivanai and S. Sasidharan. Cassia spectabilis (DC) Irwin et Barn: a promising traditional herb in health improvement. Molecules 17: 10292-10305, 2012.

Karim, A.A. and A. Azlan. Fruit pod extracts as a source of nutraceuticals and pharmaceuticals. Molecules 17: 11931-11946, 2012.

Klein, J.A. and S.L. Ackerman. Oxidative stress, cell cycle, and neurodegeneration. J. Clin. Invest. 111: 785-793, 2003.

Kusumoto, I., I. Shimada, N. Kakiuchi, M. Hattori, T. Namba and S. Supriyatna. Inhibitory effects of Indonesian plant extracts on reverse transcriptase of an RNA tumour virus (I). Phytother. Res. 6: 241-244, 1992.

Liao, J.C., J.S. Deng, C.S. Chiu, S.S. Huang, W.C. Hou, W.C. Lin and G.J. Huang. Chemical compositions, anti-inflammatory, antiproliferative and radical-scavenging activities of Actinidia callosa var. ephippioides. Am. J. Chin. Med. 40: 1047-1062, 2012. 
Lipton, P. Ischemic cell death in brain neurons. Physiol. Rev. 79: 1431-1568, 1999.

Mahajan, N., P. Joshi, M. Kondawar, K.L. Senthil Kumar and V. Vaidhyalingam Anti-nociceptive potential of Scurrula parasitica: an unexploited parasitic plant. Res Rev J. Pharmacol. 3: 4-8, 2013.

McCreadie, R.G. Diet, smoking and cardiovascular risk in people with schizophrenia descriptive study. Br. J. Psychiatry 183: 534-539, 2003.

McQuade, T., A. Tomasselli, L. Liu, V. Karacostas, B. Moss, T. Sawyer, R. Heinrikson and W. Tarpley. A synthetic HIV-1 protease inhibitor with antiviral activity arrests HIV-like particle maturation. Science 247: 454-456, 1990.

Okuda, T. and T. Yoshida. Coriamyrtin. XI. Stereochemistry of coriamyrtin and problems of derivatives. Chem. Pharm. Bull. 15: 1697-1704, 1967 a.

Okuda, T. and T. Yoshida. The correlation of coriamyrtin and tutin, and their absolute configurations. Chem. Pharm. Bull. 15: 1955-1965, 1967b.

Okuda, T., T. Yoshida, X. Chen, J. Xie and M. Fukushima. Corianin from Coriaria japonica A-Gray, and sesquiterpene lactones from Loranthus parasiticus Merr. used for treatment of schizophrenia. Chem. Pharm. Bull. 35: 182-187, 1987.

Osadebe, P., G. Okide and I. Akabogu. Study on anti-diabetic activities of crude methanolic extracts of Loranthus micranthus (Linn.) sourced from five different host trees. J. Ethnopharmacol. 95: 133-138, 2004.

Otake, T., H. Mori, M. Morimoto, N. Ueba, S. Sutardjo, I.T. Kusumoto, M. Hattori and T. Namba. Screening of Indonesian plant extracts for anti-human immunodeficiency virus-type 1 (HIV1) activity. Phytother. Res. 9: 6-10, 1995.

Pallab, K.H., B. Moulisha, B. Sanjib, K.K. Tarun and K.G. Ashoke. Hepatoprotective activity of Dregea volubilis fruit against paracetamol-induced liver damage in rats. Indian J. Pharm. Educ. 46: 20, 2012.

Peet, M. Diet, diabetes and schizophrenia: review and hypothesis. Br. J. Psychiatry 184: s102-s105, 2004.

Pierce, G.B., R.E. Parchment and A.L. Lewellyn. Hydrogen peroxide as a mediator of programmed cell death in the blastocyst. Differentiation 46: 181-186, 1991.

Powell, C.B., P. Fung, J. Jackson, J. Dall'Era, D. Lewkowicz, I. Cohen and K. Smith-McCune. Aqueous extract of herba Scutellaria barbatae, a chinese herb used for ovarian cancer, induces apoptosis of ovarian cancer cell lines. Gynecol. Oncol. 91: 332-340, 2003.

Qin, Y., T. Mo, X. Liu, Z. Pan and M. Ye. Effects of Loranthus parasiticus on nutrition metabolism of Osmanthus fragrans and Cinnamomum Burmannii. Xibei Zhiwu Xuebao 4: 034, 2010.

Seelmeier, S., H. Schmidt, V. Turk and K. Von Der Helm. Human immunodeficiency virus has an aspartic-type protease that can be inhibited by pepstatin A. Proc. Natl. Acad. Sci. USA 85: 6612-6616, 1988.

Li, Y.-S., S.-X. Fu, Y. Han and K.-F. Tseng. The diuretic action of the flavonearabinoside isolated from Chinese drug Kwang-Chi-Sheng Loranthus Parasiticus L. (Merr.). Acta Pharm. Sin. 1: 01, 1959.

Sohn, J.H., K.L. Han, J.H. Choo and J.K. Hwang. Macelignan protects HepG2 cells against tertbutylhydroperoxide-induced oxidative damage. Biofactors 29: 1-10, 2007.

Sohn, S.H., H. Lee, J.Y. Nam, S.H. Kim, H.J. Jung, Y. Kim, M. Shin, M. Hong and H. Bae. Screening of herbal medicines for the recovery of cisplatin-induced nephrotoxicity. Environ. Toxicol. Pharm. 28: 206-212, 2009.

Sullivan, P.F., K.S. Kendler and M.C. Neale. Schizophrenia as a complex trait: evidence from a metaanalysis of twin studies. Arch. Gen. Psychiatry 60: 1187, 2003.

Tang, Y., Y. Xie, H. Chai and Q. Chen. A kindling model of epilepsy induced by intraperitoneal injection of coriaria lactone in rats. J. West China Univ. Med. Sci. 21: 304, 1990. 
Uehara, T., T. Miyoshi, N. Tsuchiya, K. Masuno, M. Okada, S. Inoue, M. Torii, J. Yamate and T. Maruyama. Comparative analysis of gene expression between renal cortex and papilla in nedaplatin-induced nephrotoxicity in rats. Hum. Exp. Toxicol. 26: 767-780, 2007.

Vidal-Russell, R. and D.L. Nickrent. Evolutionary relationships in the showy mistletoe family (Loranthaceae). Am. J. Bot. 95: 1015-1029, 2008.

Wang, C.Z., T. Calway and C.S. Yuan. Herbal medicines as adjuvants for cancer therapeutics. Am. J. Chin. Med. 40: 657-669, 2012.

Wang, H.Y., L.W. Qi, C.Z. Wang and P. Li. Bioactivity enhancement of herbal supplements by intestinal microbiota focusing on ginsenosides. Am. J. Chin. Med. 39: 1103-1115, 2011.

Wong, D.Z.H. and H.A. Kadir. Antioxidative and neuroprotective effects of Loranthus parasiticus (L.) Merr (Loranthaceae) against oxidative stress in NG108-15 cells. J. Med. Plant Res. 5: 6291-6298, 2011.

Wong, D.Z.H., H.A. Kadir, C.L. Lee and B.H. Goh. Neuroprotective properties of Loranthus parasiticus aqueous fraction against oxidative stress-induced damage in NG108-15 cells. J. Nat. Med. 66: 544-551, 2012a.

Wong, D.Z.H., H.A. Kadir and S.K. Ling. Bioassay-guided isolation of neuroprotective compounds from Loranthus parasiticus against $\mathrm{H} 2 \mathrm{O} 2$-induced oxidative damage in NG108-15 cells. J. Ethnopharmacol. 139: 256-264, 2012b.

World Health Organization (WHO). http://www.who.int/mental_health/management/schizophrenia/ en/. Accessed 2013.

Wu, C. and G. Zhang. Quantitative analysis of sesquiterpene lactone in Loranthus parasiticus (L.) Merr. Parasitizing on Coriaria sinica Maxim and in seeds of Coriaria sinica Maxim. Acta Pharm. Sin. 19: 56, 1984.

Wu, Y., L. Li, T. Wen and Y.Q. Li. Protective effects of echinacoside on carbon tetrachloride-induced hepatotoxicity in rats. Toxicology 232: 50-56, 2007.

Xiao, Y., Chen Y., Chen B., Chen J., Lin Z. and Fan Y. Study on cytotoxic activities on human leukemia cell line HL-60 by flavonoids extracts of Scurrula parasitica from four different host trees. China J Chin. Mater. Med. 33: 427-432, 2008.

Xiao, Y., Fan Y., Chen B., Zhang Q. and Zeng H. Polysaccharides from Scurrula parasitica L. inhibit sarcoma S180 growth in mice. China J Chin. Mater. Med. 35: 381-384, 2010.

Xu, H.X., M. Wan, B.N. Loh, O.L. Kon, P.W. Chow and K.Y. Sim. Screening of traditional medicines for their inhibitory activity against HIV-1 protease. Phytother. Res. 10: 207-210, 1996.

Xutian, S., J. Zhang and W. Louise. New exploration and understanding of traditional Chinese medicine. Am. J. Chin. Med. 37: 411-426, 2009.

Yang, L.L., K.Y. Yen, Y. Kiso and H. Hikino. Antihepatotoxic actions of Formosan plant drugs. J. Ethnopharmacol. 19: 103-110, 1987.

Zhang, X.Q., J.H. Kim, G.S. Lee, H.B. Pyo, E.Y. Shin, E.G. Kim and Y.H. Zhang. In vitro antioxidant and in vivo anti-inflammatory activities of Ophioglossum thermale. Am. J. Chin. Med. 40: 279-293, 2012.

Zhao, H., X. Wan and J.X. Chen. A mini review of traditional Chinese medicine for the treatment of depression in China. Am. J. Chin. Med. 37: 207-213, 2009.

Zhou, H., Y.H. Tang and Y. Zheng. A new rat model of acute seizures induced by tutin. Brain Res. 1092: 207-213, 2006.

Zhou, H., Z. Zeng, R. Liu and Z. Chi. Purification and characterization of a cytotoxin from Loranthus Parasiticus Merr. Sichuan Daxue Xuebao 30: 102-106, 1993.

Zhou, H., Y. Zheng and Y. Tang. Tutin-induced epileptiform discharge of CA1 pyramidal cells in rat hippocampal slices. Acta Physiol. Sin. 56: 341, 2004. 